\title{
NeuroRegulation
}

\section{Editorial - Volume 3, Number 1}

Citation: Cannon, R. L. (2016). Editorial - Volume 3, Number 1. NeuroRegulation, 3(1), 2. http://dx.doi.org/10.15540/nr.3.1.2

Copyright: @ 2016. Cannon. This is an Open Access article distributed under the terms of the Creative Commons Attribution License (CC-BY).
*Address correspondence to: Rex L. Cannon, PhD, BCN, Neural Potential, 10151 Enterprise Center Blvd, Ste 207, Boynton Beach, FL 33437, USA. Email: rex.cannon@neuralpotential.com
Welcome to NeuroRegulation, Volume 3, Number 1. We have experienced a growing interest by both clinicians and researchers submitting quality works to our journal and hope to see this trend continue. It is interesting to note that a search on the term neurofeedback in Pubmed returns 870 articles. This is not only important to the field of neurofeedback and its growing application across numerous disciplines; it is a sign of growth and success in our respective craft. We envision NeuroRegulation being a primary source for publishing data concerning neurofeedback, self-regulation, and applied neurosciences across disciplines in a short amount of time. We encourage all researchers, clinicians, students, and theorists to publish your work in NeuroRegulation.

The current issue is comprised of a variety of topics pertaining to neurofeedback and applied neuroscience. Dr. Lauren Frey presents pilot data demonstrating the effects of SMR neurofeedback on quality of life in medically refractory seizures. Drs. Alycia Roberts, Paul Fillmore, and Scott Decker present research discussing the clinical applicability of test-retest reliability of qEEG coherence. Drs. Hsin-Yi Tsai, Erik Peper, and I-Mei Lin present research evaluating the effects of posture on the EEG during emotional recall tasks. Drs. Marcie Zinn, Mark Zinn, and Leonard Jason provide a review of Myalgic Encephalomyelitis and functional network correlates. Finally, Dr. Randall Lyle presents a book review of "The Good Life: Wellbeing and the New Science of Altruism, Selfishness and Immorality."

NeuroRegulation thanks these authors for their valuable contributions to the scientific literature for neurofeedback and quantitative EEG. We strive for high quality and interesting empirical topics. We encourage the members of ISNR and other biofeedback and neuroscience disciplines to consider publishing with us. We are planning a special issue later in the year and will be soliciting papers from experts in the field in the near future. We thank you for reading NeuroRegulation!

Rex L. Cannon, PhD, BCN

Editor-in-Chief

Email: rexcannon@gmail.com

Published: March 9, 2016 